\title{
Penerapan Modul RF 433 dalam Pengukuran Intensitas Cahaya Menggunakan Sensor LDR Berbasis Arduino
}

\author{
Rifqi Firmansyah, Satria Bagaskara, Rachmat Agus Kurdyanto, M. Nur Fatah Muizz \\ Jurusan Teknik Elektro, Fakultas Teknik Universitas Negeri Surabaya \\ rifqifirmansyah@unesa.ac.id \\ satria@gmail.com
}

\begin{abstract}
Abstrak - Intensitas Cahaya merupakan salah satu faktor penting dalam Pembangkit listrik tenaga surya. Dalam rangka mengetahui intensitas dari cahaya dalam suatu area maka di rancanglah sebuah sistem pengukuran intensitas cahaya berbasis Arduino Uno R3. Menggunakan sensor LDR (Light Dependent Resistor) dan di kirim melalui RF 433. Penelitian ini menghasilkan sebuah instrument komunikasi jarak jauh menggunakan radio frekuensi $433 \mathrm{MHz}$ sebagai pengirim dan penerima intensitas cahaya yang dikendalikan oleh Arduino UNO. Sensor intensitas cahaya memanfaatkan LDR (Light Dependent Resistor) yang mengubah jarak intensitas cahaya menjadi tegangan. Pada penelitian ini didapatkan jarak terjauh telemetri yang dapat dijangkau adalah 21 meter. Sedangkan dengan ditambahkan penghalang berupa dinding, didapatkan jarak terjauh telemetri yang dapat dijangkau adalah 12,4 meter.
\end{abstract}

Kata Kunci: Radio Frekuensi 433,Arduino UNO, LDR (Light Dependent Resistor), Telemetri.

\begin{abstract}
Light intensity is one of the important factors in the solar power plant. In order to determine the intensity of light in an area then design a system of measurement of light intensity based on the Arduino Uno R3. Using the sensor LDR (Light Dependent Resistor) and sent via RF 433. The study produced a communication instrument remotely using radio frequency transmitter and receiver 433 as the light intensity is controlled by Arduino UNO. Light intensity sensor utilizing LDR (Light Dependent Resistor) that converts light intensity to a voltage range. The Result of this research that the furthest distance of telemetry that can be reached is 21 meters. By adding obstacle of walls, obtained furthest distance of telemetry that can be reached is $\mathbf{1 2 . 4}$ meters.
\end{abstract}

Keywords: Telemetry, Temperature Sensor, Arduino, DHT11, Transmitter and Receiver, RF433MHz.

\section{PENDAHULUAN}

Cahaya merupakan sejenis energi berbentuk gelombang elekromagnetik yang bisa dilihat dengan mata. Cahaya diperlukan dalam kehidupan sehari-hari. Matahari adalah sumber cahaya utama di bumi. Tumbuhan hijau memerlukan cahaya untuk membuat makanan. Sinar dari matahari yang datang dapat disebut sebagai sinar alami. Sifat-sifat cahaya ialah, cahaya bergerak lurus ke semua arah.

Dengan memanfaatkan berbagai macam komponen elektronika, kita dapat membuat berbagai macam rangkaian yang bisa dimanfaatkan untuk berbagai keperluan. Sesuai dengan namanya, rangkaian sensor cahaya tentu saja bekerja dengan memanfaatkan cahaya dalam mempengaruhi cara kerja sebuah rangkaian.

LDR (Light Dependent Resistor) merupakan suatu sensor yang apabila terkena cahaya maka tahanannya akan berubah. Dengan memanfaatkan komponen tersebut kita dapat merancang sebuah rangkaian sensor cahaya untuk berbagai keperluan seperti sensor anti maling, sensor lampu taman, sensor lampu rumah, sensor lampu mobil, atau yang lebih keren bisa dimanfaatkan untuk rangkaian yang bisa diprogram, robot dan lain lain. Untuk mengukur intensitas cahaya menggunakan arduino, anda harus mengubah perubahan resistansi LDR menjadi perubahan tegangan (DC) karena arduino hanya mengukur tegangan, tidak bisa mengukur resistansi. Oleh karena itu dibutuhkan rangkaian sederhana "pembagi tegangan"yang komponennya adalah LDR dan resistor yang dihubungkan secara seri dan ditengah-tengahnya diumpankan ke pin analog Arduino.

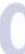

\section{TINJAUAN PUSTAKA}

Dalam pengukuran intensitas cahaya berbasis Telemetri ini, komponen yang akan digunakan adalah RF module board $433 \mathrm{MHz}$, sensor cahaya (LDR), arduino uno, microsoft visual basic 2010 dan Arduino Development Invironment.

\subsection{RF Module Board $433 \mathrm{MHz}$}

Modul RF 433 ini harganya cukup terjangkau sehingga cocok untuk digunakan untuk komunikasi menggunakan frekuensi radio (RF). Hal yang perlu diperhatikan jika menggunakan modul ini adalah kerentanannya terhadap noise yang dapat mengganggu komunikasi. Gambar 1 merupakan bentuk fisik modul RF 433. Adapun spesifikasi modul dapat dilihat di Tabel 1. 


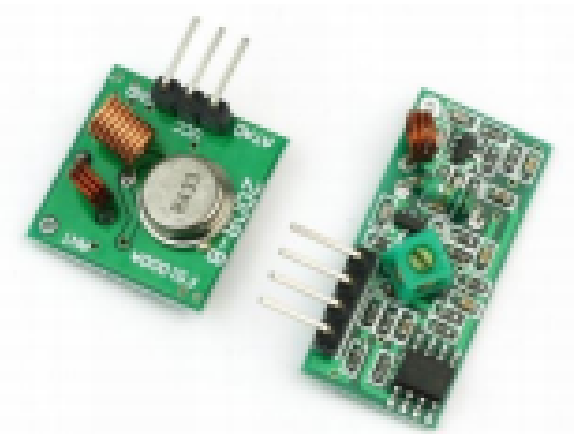

Gambar 1 Modul RF $433 \mathrm{MHz}$

Tabel 1 Spesifikasi Arduino UNO R3 Transmitter

\begin{tabular}{|c|c|}
\hline Model & MX-FS-03V \\
\hline Tegangan & $3.5 \mathrm{~V}$ \\
\hline Ukuran & $19 * 19 \mathrm{~mm}$ \\
\hline Mode Kerja & AM \\
\hline Kecepatan & $4 \mathrm{~KB} / \mathrm{S}$ \\
\hline Transmisi & \\
\hline Daya Transmisi & $10 \mathrm{~mW}$ \\
\hline Frekuensi & $433 \mathrm{MHz}$ \\
\hline Antenna & $25 \mathrm{~cm}$ \\
\hline \multirow{2}{*}{ Pin } & dari kiri ke $\mathrm{k}$ \\
\hline & Receiver \\
\hline Model & MX-05V \\
\hline Supply Tegangan & DC5V \\
\hline Arus & $4 \mathrm{~mA}$ \\
\hline Frekuensi & $433.92 \mathrm{MHz}$ \\
\hline Sensitifitas & $105 \mathrm{~dB}$ \\
\hline Antena & $32 \mathrm{~cm}$ \\
\hline Ukuran & $30 * 14 * 7 \mathrm{~mm}$ \\
\hline
\end{tabular}

Untuk tegangan, modul ini cukup fleksibel dan dapat bekerja pada rentang tegangan $3-12 \mathrm{~V}$ sehingga dapat dengan mudah digunakan pada tegangan $5 \mathrm{~V}$ sesuai dengan yang digunakan oleh arduino pada umumnya. Anda dapat menggunakan tegangan yang lebih tinggi jika ingin meningkatkan jangkauan modul ini, tentunya dengan tambahan beberapa komponen diskrit agar tidak merusak arduino yang Anda gunakan.

\subsection{Sensor Cahaya/Light Dependent Resistor (LDR)}

LDR merupakan suatu sensor yang apabila terkena cahaya maka tahanannya akan berubah. Biasanya LDR dibuat berdasarkan kenyataan bahwa film cadmium sulfide mempunyai tahanan yang besar kalau tidak terkena cahaya dan tahanannya akan menurun kalau permukaan film itu terkena cahaya. Bentuk fisik dari LDR dapat dilihat pada Gambar 2. adapun spesifikasi LDR disajikan pada Tabel 2
Tabel 2 Spesifikasi LDR

\begin{tabular}{cc} 
Supply Voltage & $5 \mathrm{VDC}$ \\
\hline Resistance Range & $200 \mathrm{~K} \Omega-500 \Omega$ \\
\hline Interface & Analog
\end{tabular}

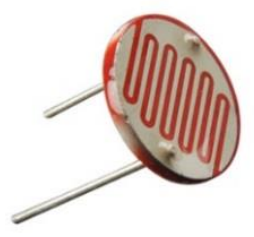

Gambar 2 LDR (Light Dependent Resistor)

Fotoresistor adalah komponen elektronika yang resistansinya akan menurun jika ada perubahan intensitas cahaya yang mengenainya .Fotoresistor dibuat dari semikonduktor beresistansi tinggi. Jika cahaya/foton dengan frekuensi yang cukup tinggi diserap oleh semikonduktor menyebabkan elektron dengan energi yang cukup untuk meloncat kepita konduksi. Elektron bebas yang dihasilkan akan mengalirkan listrik, sehingga menurunkan resistansinya. Besar tahanan LDR/fotoresistor dalam kegelapan mencapai jutaan Ohm dan turun sampai beberapa ratus Ohm dalam keadaan terang. LDR dapat digunakan dalam suatu jaringan kerja pembagi potensial yang menyebabkan terjadinya perubahan tegangan kalau sinar yang datang berubah.

\subsection{Arduino Uno}

Arduino Uno adalah arduino board yang menggunakan mikrokontroler ATmega328. Arduino Uno memiliki 14 pin digital (6 pin dapat digunakan sebagai output PWM), 6 input analog, sebuah $16 \mathrm{MHz}$ osilator kristal, sebuah koneksi USB, sebuah konektor sumber tegangan, sebuah header ICSP, dan sebuah tombol reset. Arduino Uno memuat segala hal yang dibutuhkan untuk mendukung sebuah mikrokontroler. Hanya dengan menhubungkannya ke sebuah komputer melalui USB atau memberikan tegangan DC dari baterai atau adaptor AC ke DC sudah dapat membuanya bekerja. Arduino Uno menggunakan ATmega16U2 yang diprogram sebagai USB-toserial converter untuk komunikasi serial ke computer melalui port USB. Tampak atas dari arduino uno dapat dilihat pada Gambar 3 dan Tabel 3 merupakan spesifikasi dari Arduino uno.

Tabel 3 Spesifikasi Arduino UNO R3

\begin{tabular}{lc} 
Operating Voltage & 5 VDC \\
\hline Rekomendasi input voltage & $7-12 \mathrm{VDC}$ \\
\hline Batas input voltage & $6-20 \mathrm{VDC}$ \\
\hline Input/output digital & $14 \mathrm{buah}$ \\
\hline Input analog & $6 \mathrm{buah}$ \\
\hline DC Current setiap pin I/O & $40 \mathrm{~mA}$
\end{tabular}




\begin{tabular}{lc} 
DC current untuk pin $3.3 \mathrm{~V}$ & $50 \mathrm{~mA}$ \\
\hline Flash memory & $32 \mathrm{~KB}$ \\
\hline SRAM & $2 \mathrm{~KB}$ \\
\hline EEPROM & $1 \mathrm{~KB}$ \\
\hline Clock Speed & $16 \mathrm{MHz}$
\end{tabular}

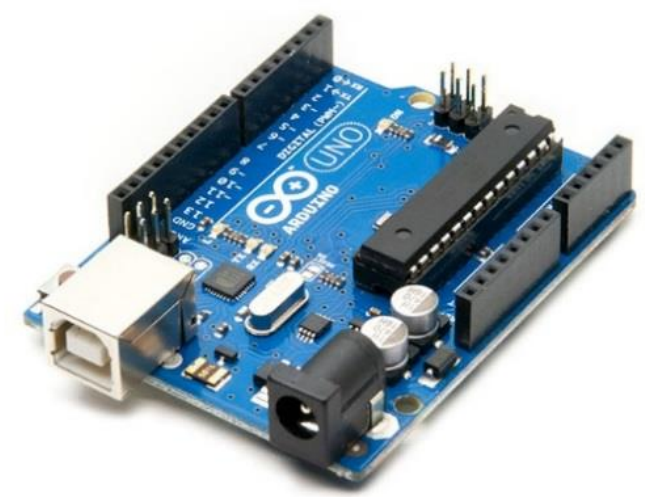

Gambar 3 Arduino UNO R3

Masing-masing dari pin digital arduino uno dapat digunakan sebagai masukan atau keluaran menggunakan fungsi pinMode(), digitalWrite() dan digitalRead(). Setiap pin beroperasi pada tegangan 5 volt. Setiap pin mampu menerima atau menghasilkan arus maksimum sebasar $40 \mathrm{~mA}$ dan memiliki 10 resistor pull-up internal (diputus secara default) sebesar 20-30 K $\Omega$. Sebagai tambahan, beberapa pin masukan digital memiliki kegunaan khusus yaitu :

1. Komunikasi serial: pin 0 (RX) dan pin 1 (TX), digunakan untuk menerima(RX) dan mengirim(TX) data secara serial.

2. External Interrupt: pin 2 dan pin 3, pin ini dapat dikonfigurasi untuk memicu sebuah interrupt pada nilai rendah, sisi naik atau turun, atau pada saat terjadi perubahan nilai.

3. Pulse-width modulation (PWM): pin 3,5,6,9,10 dan 11, menyediakan keluaran PWM 8-bit dangan menggunakan fungsi analogWrite().

4. Serial Peripheral Interface (SPI): pin 10 (SS), 11 (MOSI), 12 (MISO) dan 13 (SCK), pin ini mendukung komunikasi SPI dengan menggunakan SPI library.

5. LED: pin 13, terdapat built-in LED yang terhubung ke pin digital 13. Ketika pin bernilai HIGH maka LED menyala, sebaliknya ketika pin bernilai LOW maka LED akan padam.

Arduino Uno memiliki 6 masukan analog yang diberi label A0 sampai A5, setiap pin menyediakan resolusi sebanyak 10 bit (1024 nilai yang berbeda). Secara default pin mengukur nilai tegangan dari ground $(0 \mathrm{~V})$ hingga $5 \mathrm{~V}$, walaupun begitu dimungkinkan untuk mengganti nilai batas atas dengan menggunakan pin AREF dan fungsi analogReference(). Sebagai tambahan beberapa pin masukan analog memiliki fungsi khusus yaitu pin A4 (SDA) dan pin A5 (SCL) yang digunakan untuk komunikasi Two Wire Interface (TWI) atau
Inter Integrated Circuit (I2C) dengan menggunakan Wire library.

\section{METODE}

Sistem telemetri dibagi menjadi dua yaitu transmitter dan receiver. Pada bagian transmitter terdiri dari komponen sensor LDR, Arduino Uno dan transmitter RF Module Board $433 \mathrm{MHz}$, sedangkan pada bagian receiver terdiri dari komponen receiver RF Module Board $433 \mathrm{MHz}$, Arduino Uno dan Laptop dengan aplikasi Visual Basic sebagai GUI.

Sistem telemetri secara keseluruhan dalam penelitian ini terdiri dari perancangan sensor LDR, perancangan transmitter, perancangan receiver dan perancangan GUI seperti yang ditunjukkan pada Gambar 4.

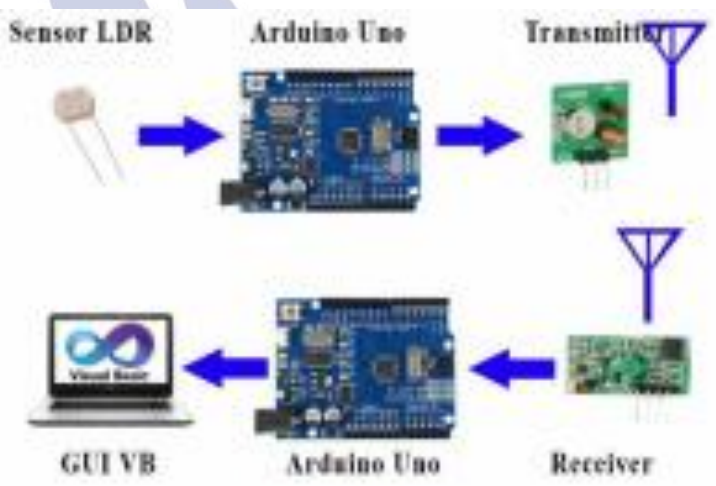

Gambar 4 Blok Sistem Rangkaian Telemetri

\subsection{Perancangan Sensor LDR}

Perancangan sensor LDR pada penelitian ini yaitu memasangkan sensor LDR dengan Resistor $220 \Omega$ sehingga membentuk suatu voltage divider (pembagi tegangan). Input dari sensor LDR diukur pada titik cabang antara sensor LDR dan resistor. Nilai yang terbaca tergantung dari intensitas cahaya yang masuk. Rangkaian sensor LDR dapat dilihat pada Gambar 5.

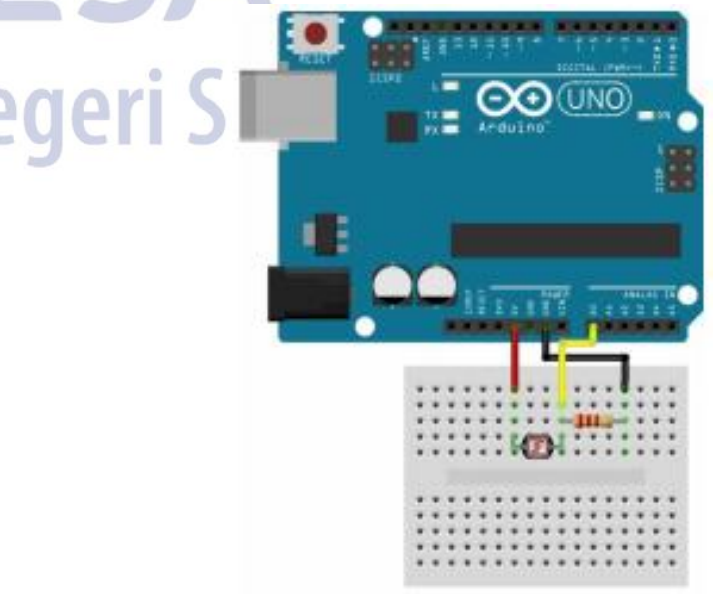

Gambar 5 Rangkaian sensor LDR 


\subsection{Perancangan Transmitter}

Perancangan transmitter pada penelitian ini yaitu menggabungkan antara rangkaian sensor LDR dengan rangkaian transmitter dapat dilihat pada Gambar 6. Nilai yang dihasilkan dari sensor LDR akan diproses oleh Arduino untuk diolah menjadi suatu data, kemudian data tersebut akan dikirimkan oleh Arduino Uno pada receiver melalui RF Module Board $433 \mathrm{MHz}$ Transmitter. Gabungan rangkaian transmitter dan LDR dapat dilihat pada gambar 7.

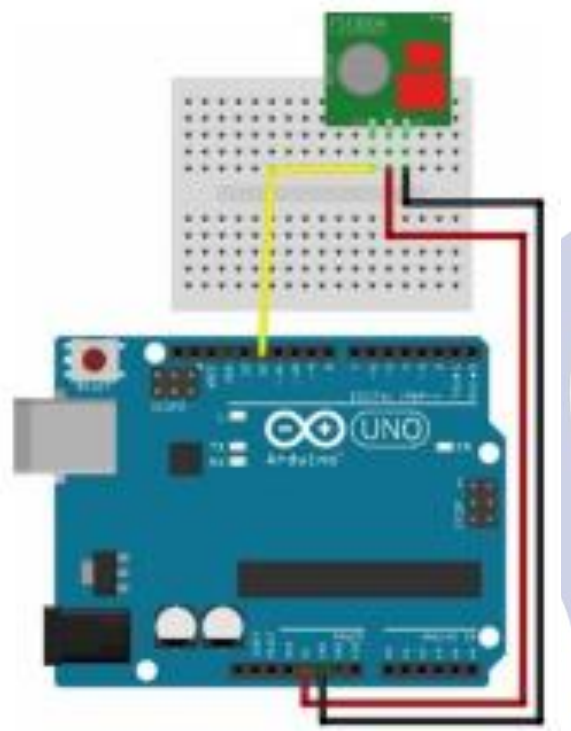

Gambar 6 Rangkaian Transmitter

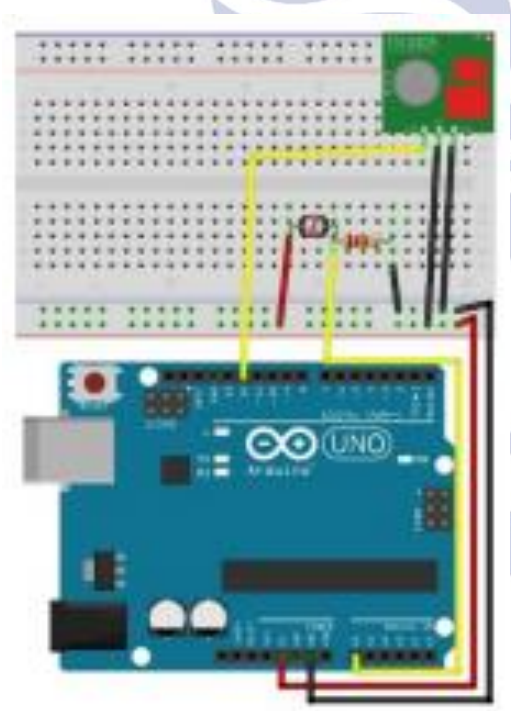

Gambar 7 Gabungan Rangkaian sensor LDR dan

Rangkaian Transmitter

\subsection{Perancangan Receiver}

Perancangan Receiver pada penelitian ini yaitu RF Module Boar $433 \mathrm{MHz}$ Receiver dirangkai dengan menggunakan Arduino yang berbeda dengan perancangan transmitter, rangkaian transmitter disambungkan ke komputer/laptop untuk proses menampilkan data. Receiver menerima data dari transmitter, data tersebut selanjutnya akan diolah oleh Arduino Uno pada rangkaian receiver untuk ditampilkan ke layar monitor. Rangkaian receiver dapat diliha pada gambar 8 .
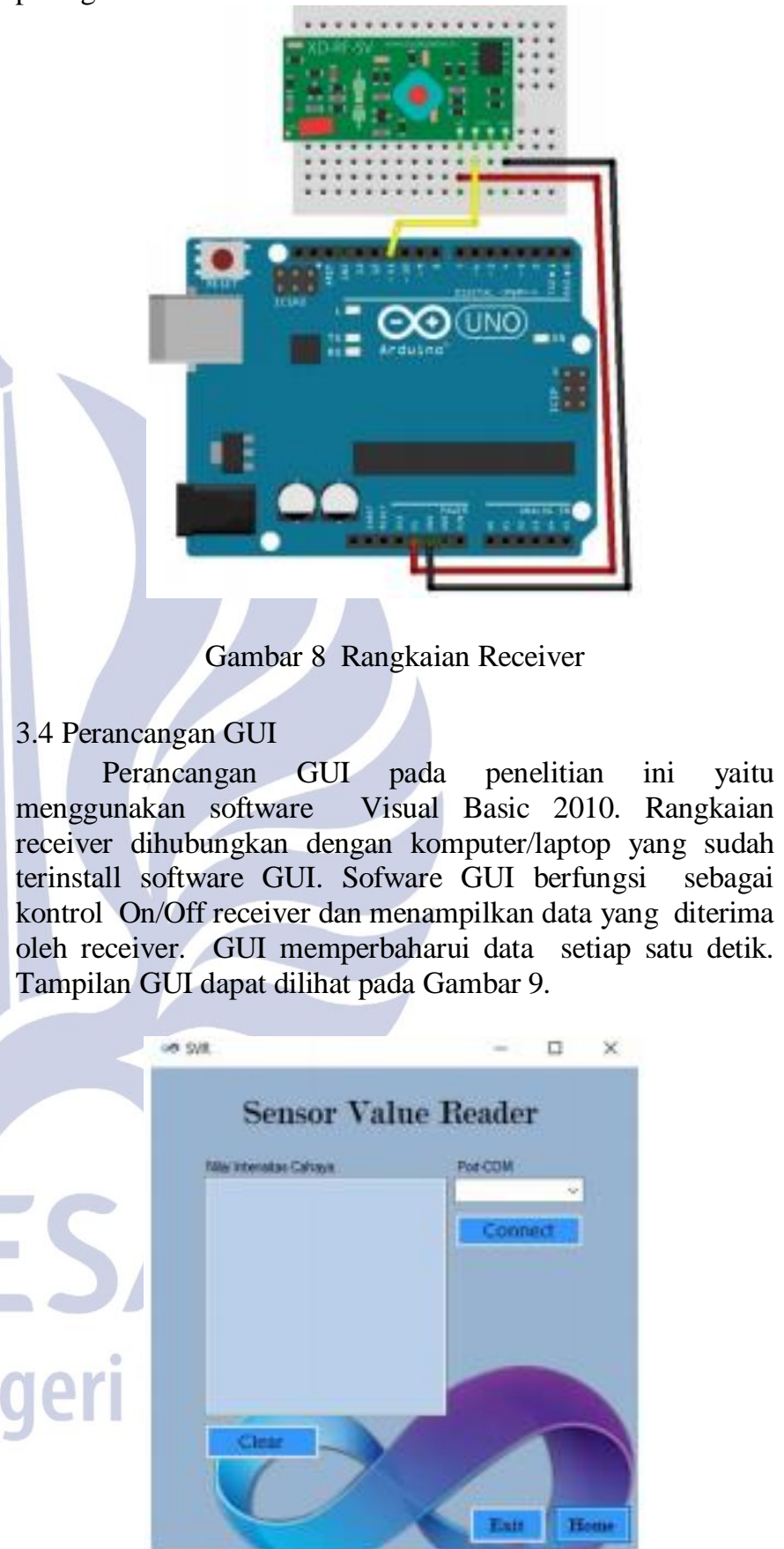

Gambar 9 Tampilan GUI Menggunakan Visual Basic 2010

\section{PENGUJIAN DAN PEMBAHASAN}

Pengujian dari penelitian ini meliputi pengujian sensor LDR dan pengujian jarak transmisi modul RF 433 dengan penghalang maupun tanpa penghalang. 
4.1 Pengujian Sensor LDR

Pengujian ini bertujuan untuk menyesuaikan hasil pembacaan sensor LDR dengan hasil pembacaan LUX, mengetahui besar error yang dihasilkan oleh pembacaan sensor LDR dan untuk mengetahui kemampuan sensor LDR terhadap perubahan intensitas cahaya. Hasil yang didapatkan disajikan pada Tabel 4.

Tabel 4. Pengujian dan kalibrasi pada sensor LDR

\begin{tabular}{cccc} 
No & Lux & LDR & Error \\
\hline 1 & 126 & 127.204 & 1.204 \\
\hline 2 & 126 & 127.938 & 1.938 \\
\hline 3 & 14 & 11.398 & 2.602 \\
\hline 4 & 13.4 & 12.87 & 0.53 \\
\hline 5 & 6.8 & 5.878 & 0.922 \\
\hline 6 & 4.8 & 5.144 & 0.344 \\
\hline 7 & 226.4 & 221.318 & 5.082 \\
\hline 8 & 226.4 & 222.9 & 3.5 \\
\hline 9 & 156 & 155.578 & 0.422 \\
\hline 10 & 155.6 & 156.25 & 0.65
\end{tabular}

\subsection{Pengujian Jarak Sensor Telemetri}

Pengujian ini dilakukan untuk mengetahui jarak yang dapat dijangkau antara transmitter ke receiver.dan untuk mengukur berapa kali data diterima oleh receiver selama 5 detik. Hasil yang didapatkan disajikan pada Tabel 5.

Tabel 5. Pengujian dan kalibrasi pada sensor LDR

\begin{tabular}{ccc} 
No & Jarak $(\mathrm{m})$ & Data yang diterima \\
\hline 1 & $1-2$ & $209,246,248$ \\
& & $250,250,240$ \\
& & $240,240,226$ \\
\hline 2 & $3-4$ & $237,237,238$, \\
& & $238,238,229$, \\
& & $231,231,231$, \\
& & 231 \\
\hline 3 & $5-6$ & $205,204,204$, \\
& & $205,205,205$, \\
& & 205,204, \\
\hline 4 & $7-8$ & $207,207,207$, \\
& & $207,209,191$, \\
& & $194,198,198$, \\
& & 200 \\
\hline 5 & $9-10$ & $220,220,218$, \\
& & $218,209,209$, \\
& & $211,213,213$ \\
\hline 6 & $11-12$ & $224,226,224$, \\
& & 224,227, \\
& & $233,231,231$ \\
\hline 7 & $13-14$ & $196,196,198,198,1636$, \\
& & $1654,1691,1672$ \\
\hline 8 & $15-16$ & $1268,1249,1231$, \\
& &
\end{tabular}

$1213,1419,1419$

$1419,1400,1400$,

$1512,1531,1531$,

$1512,1488,1507$, 1488,1488 ,

\begin{tabular}{ccc}
\hline 10 & $19-20$ & $1305,1323,1323$, \\
& & $1341,1253,1253$, \\
& & $1235,1253,1253$, \\
\hline 11 & 21 & $437,389,400$, \\
& & 404,406
\end{tabular}

4.3 Pengujian Sistem Telemetri dengan Penghalang dan Tanpa Penghalang

Pengujian ini dilakukan dengan memberikan halangan penutup pada transmitter yang bertujuan untuk mengetahui pengaruh halangan terhadap kemampuan sistem telemetri dalam mengirim data. Hasil yang didapatkan disajikan pada Tabel 6.

Tabel 5. Pengujian dan kalibrasi pada sensor LDR

\begin{tabular}{ccc} 
No & Tanpa Penghalang & Dengan Penghalang \\
\hline 1 & $\begin{array}{l}\text { Jarak telemetri } \\
\text { mencapai } 21\end{array}$ & $\begin{array}{c}\text { Jarak telemetri } \\
\text { mencapai 12.4 } \\
\text { meter }\end{array}$ \\
PENUTUP
\end{tabular}

\section{Simpulan}

Dari hasil peneltian dan pembahasan maka dapat disimpulkan hal - hal sebagai berikut:

1. Didapatkannya sistem transfer data berbasis telemetri dan monitoring intensitas cahaya yang dapat dikirimkan dengan medium udara.

2. Sistem transfer data yang dikembangkan mampu bekerja secara real time sehingga perubahan data yang terjadi pada data yang diukur dapat di deteksi setiap saat sehingga dapat dikatakan bahwa alat ini mempunyai tingkat keakuratan tingi dalam mendapatkan data hasil pengukuran.

3. Hasil pengukuran yang dilakukan juga membuktikan bahwa sistem transfer data dengan model telemetri dan real time dapat mendeteksi setiap perubahan intensitas cahaya yang terjadi secara real time. Dibandingkan dengan pengukuran konvensional yang menggunakan perangkat analog dan timing pengambilan data yang relative tidak bisa secara tepat setiap saat.

4. Kalibrasi dilakukan dengan membandingkan nilai dari lux meter dengan data yang dibaca sensor LDR. Pada kegiatan ini, didapatkan rata-rata error data sebesar 1.719.

5. Dari hasil penelitian dan pengujian dapat disimpulkan bahwa sistem telemetri menggunakan RF $433 \mathrm{MHz}$ dapat mengirim data pada jarak maksimal 21 meter tanpa adanya penghalang, sedangkan dengan penghalang dapat mengirimkan data pada jarak maksimal 12.4 meter. 


\section{DAFTAR PUSTAKA}

[1] Berk, R.A. (Ed.). 1984. A Guide Criterion Referenced Test Contruction. Baltimore: The John Hopkins University Press.

[2] Airasian, P.W. 1970. "The use of hierarchies in the analysis and planning of chemistry instruction". Science Education, 54. (91-95)..

[3] Firmansyah, Rifqi. 2017. Rancang Bangun Trainer Telemetri Sebagai Media Pembelajaran Matakuliah Telemetri Dan Kontrol Di Jurusan Teknik Elektro Unesa. Jurnal Pendidikan Teknik Elektro. Vol. 6 No. 1 Thn. 2017

[4] Shafiudin S., Rohma F., Prasetya A., Firmansyah, Rifqi. 2016. Pemantauan Ruang Inkubator Penetasan Telur Ayam Dengan Berbasis Telemetri Menggunakan Arduino Uno R3. Jurnal Nasional Teknik Elektro. Vol. 5 No. 1 Thn. 2016

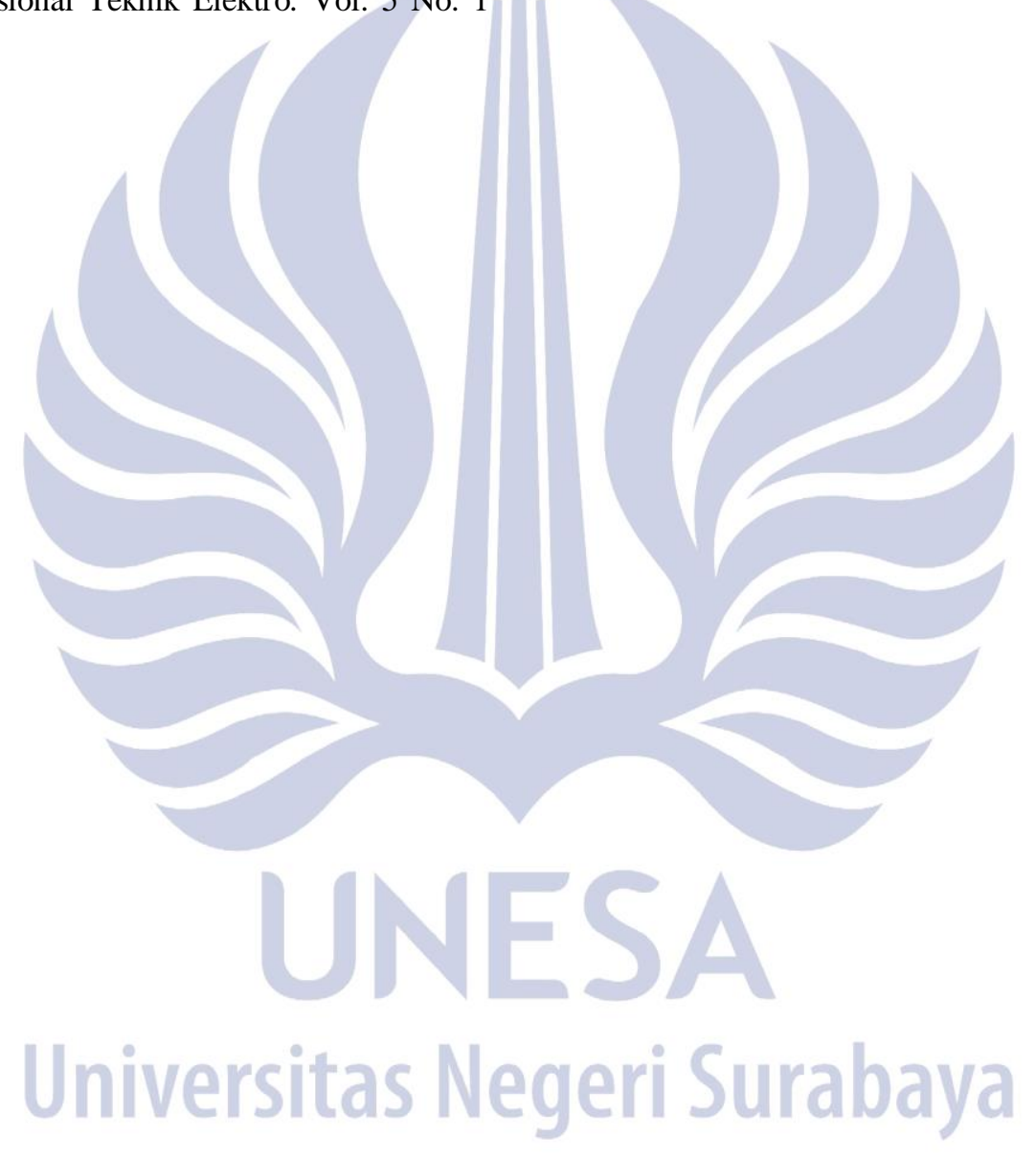

